\title{
Configurações
}

Revista Ciências Sociais

19 | 2017

Vária

\section{O passado por dentro do presente: Guerra Colonial portuguesa e as reescritas da memória cultural}

The past inside the present: the Portuguese Colonial War and the rewriting of the cultural memory

Le passé dans le présent : la guerre coloniale portugaise et les réécritures de la mémoire culturelle

Doris Wieser e Luciana Moreira

\section{OpenEdition}

\section{Journals}

Edição electrónica

URL: http://journals.openedition.org/configuracoes/4022

DOI: $10.4000 /$ configuracoes. 4022

ISSN: 2182-7419

\section{Editora}

Centro de Investigação em Ciências Sociais

\section{Edição impressa}

Paginação: 89-103

ISSN: 1646-5075

\section{Refêrencia eletrónica}

Doris Wieser e Luciana Moreira, «O passado por dentro do presente: Guerra Colonial portuguesa e as reescritas da memória cultural », Configurações [Online], 19 | 2017, posto online no dia 30 junho 2017, consultado o 10 dezembro 2020. URL : http://journals.openedition.org/configuracoes/4022 ; DOI : https://doi.org/10.4000/configuracoes.4022 
Wieser, Doris; Moreira, Luciana - 0 passado por dentro do presente: Guerra Colonial portuguesa e as reescritas da memória cultural. Configurações, vol. 19, 2017, pp. 89-103

\title{
0 passado por dentro do presente: Guerra Colonial portuguesa e as reescritas da memória cultural
}

\author{
DORIS WIESER*
}

Universidade de Lisboa

LUCIANA MOREIRA**

Universidade de Coimbra

\section{Resumo}

Este artigo apresenta um estudo sobre a memória cultural (Aleida e Jan Assmann) e pós-memória (Hirsch, Suleiman) da Guerra Colonial Portuguesa na poesia e nas artes visuais. O corpus compreende uma série de poemas escritos pela geração que viveu a guerra em idade adulta de forma direta ou indireta (Manuel Alegre, Fiama Hasse Pais Brandão e José Niza) e obras elaboradas pelas gerações uma e meia e segunda: instalações de Ana Vidigal e uma curta-metragem de António Ferreira. O objetivo da análise prende-se com as estratégias dos artistas de destruir os pilares constitutivos da identidade nacional portuguesa, sepultando mitos nacionais, denunciando estragos emocionais e reivindicando a reescrita da memória cultural do país.

Palavras-chave: guerra colonial, identidade nacional, memória, pós-memória.

\footnotetext{
Abstract

The past inside the present: the Portuguese Colonial War and the rewriting of the cultural memory

This article focuses on the cultural memory (Aleida and Jan Assmann) and post-memory (Hirsch, Suleiman) of the Portuguese Colonial War in poetry and visual arts. The empirical support comprises both poems written by the generation that lived the war, directly or indirectly, in its adulthood (Manuel Alegre, Fiama Hasse Pais Brandão and José Niza), as well as artworks elaborated by the one-and-a-half and second "Investigadora FCT do Centro de Estudos Comparatistas da Universidade de Lisboa (CEC). E-mail: dwieser@letras.ulisboa.pt.

*:Investigadora no Centro de Estudos Sociais da Universidade de Coimbra (CES). E-mail: lucianamoreira@ces.uc.pt.
} 
generations: installations by Ana Vidigal and a short film by António Ferreira. The goal is to analyse the strategies applied by the artists to destroy the pillars of the Portuguese national identity, burying national myths, denouncing emotional damage and claiming the rewriting of the country's cultural memory.

Keywords: Portuguese Colonial War, national identity, memory, post-memory.

\section{Résumé}

Le passé dans le présent : la guerre coloniale portugaise et les réécritures de la mémoire culturelle

Cet article présente une étude sur la mémoire culturelle (Aleida et Jan Assmann) et la post-mémoire (Hirsch, Suleiman) de la guerre coloniale portugaise dans la poésie et les arts visuels. Le corpus comprend un ensemble de poèmes écrits par la génération qui a vécu la guerre à l'âge adulte de façon directe ou indirecte (Manuel Alegre, Fiama Hasse Pais Brandão et José Niza), ainsi que des ouvrages conçus par les générations un et demi et deuxième : des installations d'Ana Vidigal et un court-métrage d'António Ferreira. L'analyse porte sur les stratégies des artistes pour déconstruire les éléments constitutifs de l'identité nationale portugaise, en enterrant les mythes nationaux, en dénonçant les dommages émotionnels et en réclamant une réécriture de la mémoire culturelle du pays.

Mots-clés: Guerre Coloniale portugaise, identité nationale, mémoire, post-mémoire.

Quantos desastres dentro de um desastre. Alcácer Quibir foi sempre o passado por dentro do presente ó meu país que nunca te encontraste.

“Explicação de Alcácer Quibir”, in Manuel Alegre, O Canto e as armas, 1967

\section{Introdução: Memória cultural e identidade nacional}

A literatura Desde ainda antes do 25 de abril de 1974, centenas de obras literárias têm sido publicadas sobre a Guerra Colonial. Neste panorama, a Antologia da Memória Poética da Guerra Colonial (2011) ${ }^{1}$, organizada por Margarida Calafate Ribeiro e Roberto Vecchi, é um importante compêndio que visa a inscrição de uma seleção significativa de poemas na memória cultural portuguesa. Entretanto, surgiram novas gerações que se debruçam sobre o tema de outra maneira. Autores e autoras que nasceram durante os treze anos de Guerra Colonial e absorveram as tensões psicológicas da época enquanto crianças formam o que Susan Suleiman (2002) denominou 1.5 generation e aqueles que nasceram nos anos posteriores à Revolução dos Cravos pertencem à chamada 
“segunda geração" (Hirsch, 2008). Neste ensaio, analisaremos o modo como autores de diferentes gerações denunciam a Guerra Colonial, atacando e subvertendo elementos da identidade e do imaginário nacional portugueses. Para este efeito, escolhemos poemas de testemunhas da guerra (Manuel Alegre, Fiama Hasse Pais Brandão e José Niza) contidos na mencionada antologia. A pós-memória das gerações seguintes será analisada com base em instalações de Ana Vidigal e numa curta-metragem de António Ferreira.

Jan Assmann distingue dois tipos de memória coletiva: por um lado, a "memória comunicativa" (kommunikatives Gedächtnis), que abarca as vivências das três a quatro gerações vivas (abarcando 80 a 100 anos), e, por outro, a "memória cultural" (kulturelles Gedächtnis), que compreende elementos históricos mais afastados e armazenados exteriormente (ou seja, fora do corpo humano). A memória comunicativa constitui-se na interação informal do quotidiano: pelas histórias, imagens e emoções que se transmitem nas famílias e entre pessoas com contacto direto. Contrariamente a isso, a memória cultural apresenta um maior grau de formalidade (institucional e ritual), depende de entidades e especialistas responsáveis pela sua conservação e é formada na tensão entre poder e resistência. A sua função consiste em unir os indivíduos de uma comunidade através da constante presentificação de uma escolha de elementos de um passado comum. Ela é, portanto, "o passado por dentro do presente” do verso de Manuel Alegre citado na epígrafe. Por isso, a memória cultural armazena elementos constitutivos da identidade tanto individual, como coletiva ou nacional (Assmann, 2007: 48-56). É preciso destacar que a memória cultural visa tanto os modos de lembrança, como os modos de esquecimento. Para capturar esta dinâmica, Aleida Assmann introduziu a distinção entre "memória em função" (Funktionsgedächtnis) e "memória em depósito" (Speichergedächtnis). O primeiro termo designa aqueles elementos do passado que são lembrados numa sociedade através de tradições, ritos, livros escolares, obras canónicas de arte, monumentos, museus, etc.. O segundo termo designa os elementos que, num momento dado, estão fora de uso (dados armazenados em arquivos, bibliotecas, porões de museus, etc.), mas que podem ser resgatados e, assim, aproveitados para reescrever ou completar a memória em função (Assmann, 2006: 54-58).

O modo como uma comunidade recorda o seu passado está intimamente ligado à sua identidade. Portanto, alterações na memória cultural levam inevitavelmente a reajustes na autoimagem da comunidade. Partindo desta premissa, veremos, num primeiro passo, quais eram os elementos constitutivos da identidade nacional portuguesa durante o Estado Novo - os elementos da memória em função - para depois analisar como os poetas da Guerra Colonial os desmistificam e subvertem. 


\section{Elementos constitutivos da identidade nacional portuguesa}

Em Portugal, apesar de as fronteiras geográficas serem das primeiras a definir-se na Europa, a consciência de uma identidade nacional não foi de modo nenhum imediata. De acordo com José Mattoso (1998: 17), há alguns momentos decisivos, na maioria das vezes ligados a episódios bélicos, que foram ajudando à construção de uma noção de identidade nacional entre os portugueses, de entre os quais se podem destacar o movimento de "Reconquista", logo após a independência, ou as lutas fronteiriças entre Portugal e os reinos limítrofes de Leão e Castela. Mais tarde, as lutas pela independência, no período entre D. Fernando e D. João I, mestre de Aviz, terão também um papel fundamental, pressupondo-se até que seja dessa época a criação da lenda do Milagre de Ourique. Posteriormente, a expansão marítima portuguesa e as vitórias que daí advieram acabaram por intensificar uma espécie de orgulho nacional. Os descobrimentos reforçam essa identidade na medida em que o povo português se sente em confronto com a diversidade do outro, o que leva a que, por um lado, sinta uma maior noção de pertença a um grupo ou a uma pátria e, por outro, permite-lhe também elevar-se acima dos povos que está a colonizar, ter a importância que não lhe era atribuída pela Europa, uma vez que, por ela, sempre fora visto com "a distância de quem não é plenamente contemporâneo do espaço-tempo que ocupa” (Santos, 2006: 237).

A expansão portuguesa pelos continentes de África, Ásia e América Latina teve um papel fundamental no cimentar de uma consciência de identidade nacional entre os portugueses, mas os teóricos salvaguardam também o alcance quase elitista dessa consciencialização. José Mattoso (1998: 93), por exemplo, refere haver uma reduzida influência social nas camadas populares como indicador de que estas dificilmente teriam consciência de identidade nacional. Mas os descobrimentos vão levar a que Portugal escape à Europa que o atemoriza e construa um império além-mar, mobilizando, para essa imagem imperial de si próprio, todo o orgulho nacional que se vinha enraizando com bases, por vezes, mais míticas do que históricas. O poder político tenta, portanto, relegar a pequenez do país à memória em depósito e manter os descobrimentos na memória em função.

Um exemplo desse "excesso mítico" em detrimento da análise histórica, ou "défice de realidade" (Santos, 1999: 49), é o da batalha de Alcácer Quibir e da figura do rei D. Sebastião, paradigma de derrota efetiva e de um choque que levou à perda da independência. Ora, esse desastre vai gerar, afinal, uma utopia nacionalista que projeta Portugal como país eleito e sonha o regresso do rei desaparecido para cumprir a missão messiânica de construção de um Quinto Império tão bem delineada pela pena de Padre António Vieira. Com Jan Assmann (2007: 52), podemos chamar a estes elementos míticos "histórias fundacionais" através das quais a comunidade se certifica da sua identidade. 
Para Boaventura de Sousa Santos (2006: 211), foi a incapacidade das classes dirigentes portuguesas que levou a que Portugal adquirisse a posição de um "país semi-periférico no sistema mundial capitalista moderno, desde o século XVII”, mantendo, também devido a essa posição, um papel de intermediação entre o centro e a periferia da economia-mundo, ou seja, entre a Europa e si mesmo e entre si e as colónias que mantinha.

Para piorar o contexto português, em 1890, dá-se o Ultimatum Inglês, que vem trazer outra experiência traumática ao país na medida em que o envergonha face à Europa, retirando-lhe a almejada faixa do Oceano Atlântico até ao Índico através da pretendida união de Angola a Moçambique, demarcada por Portugal no Mapa Cor-de-Rosa. Ao ceder ao Ultimatum, a monarquia portuguesa oferece as condições para um aproveitamento político que levará à revolução republicana. Devido a esse episódio, “poucos períodos da nossa história foram tão 'patrióticos' como aquele que a República inaugurou” (Lourenço, 2009: 31), permanecendo, deste modo, o excesso mítico na noção de identidade nacional de um país que continua consciente da sua grandiosidade (memória em função) e cada vez mais inconsciente da sua condição periférica (memória em depósito). Boaventura de Sousa Santos avança a hipótese de que esta subalternidade económica e política de longa duração faz com que Portugal tenha a experiência de colonizado face a Inglaterra ou à Europa e, por isso mesmo, a "identidade imperial não lhe é outorgada por ninguém para além dele" (Santos, 2006: 229). Assim o colonizador português "é um sujeito tão desprovido de soberania quanto o (seu) colonizado" (idem, ibidem).

O Estado Novo, sob uma máscara de modéstia, vem, através da educação e também da sua máquina de propaganda nacional, criar uma "fabricação sistemática e cara de uma lusitanidade exemplar, cobrindo o presente e o passado escolhido em função da sua mitologia arcaica e reacionária" (Lourenço, 2009: 33). Assim, o Estado Novo resolveu o problema da sua diminuta imagem no presente, dando aos cidadãos a imagem de um país imperial, maior do que a própria Europa se se juntassem os mapas de todas as colónias, como aparecia num livro escolar da época, ensinando que Portugal se prolonga do Minho a Timor. Tal era a grandiosidade do Império projetada e imaginada pelo regime que Margarida Calafate Ribeiro (2004: 15) reconfigura a conceptualização de Boaventura de Sousa Santos sobre o centro e a periferia, redefinindo "o império como imaginação do centro". Assim, a história magnífica da fundação do país até à exemplaridade dos descobrimentos portugueses, uma vez mais, não passava de um império imaginado.

\section{Guerra Colonial e identidade nacional}

A Guerra Colonial portuguesa começa em Angola em 1961, impulsionada por um assalto às prisões e pelos ataques brutais da União dos Povos de Angola 
(U.P.A.) às fazendas de colonos portugueses no norte do país. Perante aqueles ataques, Oliveira Salazar pronuncia a já mítica frase "Para Angola, rapidamente e em força", demonstrando a "inevitabilidade do conflito armado" (Ribeiro, 2004: 174), uma vez que ao mítico império era impensável assumir o pedido de libertação que se lia nos ataques referidos. Mas aquilo que começa não é e não será nunca uma guerra assumida². Em 1963, processo semelhante inicia-se na Guiné, onde o Partido Africano da Independência da Guiné e Cabo Verde (P.A.I.G.C.) se mostra determinado na libertação, e em 1964 também Moçambique será palco das mesmas tentativas dos guerrilheiros da Frente de Libertação de Moçambique (FRELIMO) que traziam consigo, à luz da ideologia nacionalista de Salazar, o perigo comunista.

Deste modo, tem início um longo conflito bélico que durará de 1961 a 1974, a que apenas a revolução do 25 de abril porá fim, cansados que estavam os militares de ver partir barcos cheios de soldados para lutar numa "guerra sem sentido que o discurso oficial definia como uma missão pacificadora e civilizacional” (Ribeiro, 1998: 130). Assim, Portugal, o primeiro país europeu a lançar-se na aventura marítima, é também o último, depois de um difícil processo que vitimou milhares de soldados portugueses e ainda mais africanos, a deixar cair o seu imperialismo. Foi ao fim de treze anos de Guerra Colonial que se deu "a derrocada abrupta" do império português, após a queda de um regime com quase 50 anos de poder. Nas palavras de Eduardo Lourenço (2009: 46), essa queda deveria ter criado "na nossa consciência um traumatismo profundo" e um "repensamento em profundidade da totalidade da nossa imagem perante nós mesmos e no espelho do mundo", o que, aos olhos do pensador, não terá acontecido.

Se bem que isso seja verdade no que diz respeito à memória política stricto sensu, não podemos afirmar o mesmo em relação à memória cultural em sentido lato. Os processos de transformação da memória cultural - a flutuação de elementos da memória em função à memória em depósito, e vice-versa, e a construção de sentido - são lentos e graduais. Mas sem dúvida que a reescrita da memória cultural no campo da literatura, por oposição a discursos baseados na imperialidade do país e no esquecimento da sua própria subalternidade, bem como a denúncia da Guerra Colonial começaram há muito tempo. Prova disto são os poemas que analisaremos a seguir.

2 Para dar uma pequena prova disso, citamos um discurso de Marcello Caetano proferido na Assembleia Nacional em 27 de novembro de 1968: “Não declarámos guerra a ninguém. Não estamos em guerra com ninguém. A subversão não tem nome e os seus atentados partem não se sabe de quem. Defendemo-nos. Defendemos vidas e haveres. Defendemos, não uma civilização, mas a própria civilização" (Caetano, 1973: 11). 


\section{Memória das testemunhas da Guerra Colonial}

A literatura da Guerra Colonial escrita por quem a viveu, pertencendo, portanto, à geração que fechou o ciclo imperial português, narra a "anti-epopeia pessoal e colectiva que foi a guerra colonial” (Ribeiro, 1998: 139) e, ao mesmo tempo, põe em causa aqueles elementos (míticos) da memória em função que foram aproveitados pelo Estado Novo como justificação e legitimação da guerra. Neste sentido, surge aqui a noção de identidade fragmentada ou perdida e de questionamento da identidade portuguesa na medida em que se regressa perdedor de uma guerra que põe fim ao império português. Muitos dos que combateram, mas também os que foram recebendo apenas os ecos da guerra e que fizeram dela o tema da sua produção poética evocam a consciencialização nacional enraizada em mitos (D. Sebastião, Alcácer Quibir, o mar, os barcos, a bandeira nacional, etc.) de modo a desconstruir esse imaginário fantástico da grandiosidade portuguesa e a marcar a necessidade de Portugal regressar definitivamente das viagens que tinha empreendido. Tais são os casos de Manuel Alegre, Fiama Hasse Pais Brandão e José Niza, analisados de seguida.

Manuel Alegre foi um poeta da guerra no sentido em que tornou seu objeto poético a guerra que experienciou na pele. Quando, em 1962, foi mobilizado para Angola e aí participou numa revolta militar, deu provas do que pensava daquele conflito. Na época, a única coisa que conseguiu foi ser preso pela Polícia Internacional e de Defesa do Estado (P.I.D.E.). Mas a guerra "passou-lhe para os ossos", nas palavras de Fernando Assis Pacheco, outro poeta da guerra, e foi através da escrita que denunciou "a falsa epopeia que era a Guerra Colonial” (Ribeiro, 2004: 225). O poema "Explicação de Alcácer Quibir" (AMPGC, 2011: 343-344), publicado originalmente em O Canto e as Armas (1967), é disso exemplo. Alcácer Quibir é o desastre dos desastres e o poeta evoca a metáfora Alcácer Quibir/Guerra Colonial, para denunciar a previsibilidade da perda desta guerra. Assim, as sucessivas partidas, as sucessivas batalhas, as derrotas logo camufladas em novos sonhos de Quintos Impérios a haver, remetem para as identidades fragmentadas de um povo que pertence a um país que não se olha por dentro, construindo-se a partir de novos mitos regeneradores a cada derrota que vive e que relega, deste modo, à memória em depósito, negando-lhe importância.

Segundo o poeta, "Alcácer Quibir foi sempre/ o ires perder-te em cada Índia que ganhaste" e Índia remete aqui para todas as vitórias que levaram a que o país se dividisse a cada viagem e a cada nova conquista. Trata-se, então, da desconstrução do valor das viagens e da desconstrução da identidade de povo conquistador, pois esse partir constante levou a que se tornasse um povo de identidade fragmentada, incapaz de regressar a si. Alcácer Quibir já não é, para o sujeito poético, um mito regenerador, mas a derrota do próprio país: "as armas vencidas" (que se vão adivinhando na Guerra Colonial), "os ombros vergados”, “as horas perdidas” e, finalmente, "quinhentos anos dentro destes 
anos", ou seja, quinhentos anos de partidas e de batalhas jogados agora numa última guerra, como uma cartada final, desesperada e sem trunfos.

Manuel Alegre evoca "estes barcos que partem com homens e armas/ (...)/ para levar além do mar a guerra”, desconstruindo também esse objecto-símbolo das viagens e de uma grandiosidade imposta. Porque agora os barcos já não partem em busca de novas conquistas, antes partem levando já a morte dentro de si, na medida em que levam os soldados que vão perder a guerra, deixando para trás um Portugal também perdido de si ("E de novo perder/ além do mar o que se deixa em terra”). Alcácer Quibir é, para o poeta, “ir morrer além do mar por coisa nenhuma”, sepultando, de uma vez para sempre, a ideia de Alcácer Quibir enquanto desastre num ciclo de regeneração que colocará Portugal no centro novamente. Por fim, o poeta refere que "um fantasma é rei de Portugal”, remetendo para o fantasma de D. Sebastião, que necessita também de um jazigo definitivo e que não é, portanto, o desejado, mas sim um fantasma que faz "parar o tempo", um louco, precisamente porque não permite que Portugal avance sem o peso desse império que o verga. Mas o fantasma é também o real governador de Portugal, podendo, por isso, ver-se aí uma alusão à loucura de Salazar em manter a Guerra Colonial, forçando a viver um império moribundo.

Concluindo, o poeta faz um uso bem diferente das figuras do imaginário português contidas na memória em função e utilizadas para legitimar o império, quer sejam os barcos, quer seja D. Sebastião, quer seja a própria batalha de Alcácer Quibir, questionando “a instrumentalização da memória nacional feita pelo regime, usando-a, enquanto história e mito, num sentido profundamente diverso daquele que o Estado novo fazia" (Ribeiro, 2004: 226).

No que diz respeito a Fiama Hasse Pais Brandão, ela é das primeiras poetas a dar-se conta do que se passava além-mar. Ela e os colegas dos cadernos Poesia 61 (Gastão Cruz, Luísa Neto Jorge, Maria Teresa Horta, Casimiro de Brito) vão, de um modo muito velado, referir-se às partidas de naus e aos novos significados que o mar assume quando começam a ser enviados navios de soldados no mesmo ano em que saem os cadernos acima referidos.

Em "Barcas Novas" (1967) (AMPGC, 2011: 37-38), escrito a partir de uma barcarola de João Zorro, Brandão parte da imagem das "barcas”, antes usadas por Portugal na expansão e nas rotas comerciais. No poema, as barcas transformam-se em sinal de morte anunciada, pois partem "lavradas de armas", "lavradas de homens" e "levam guerra". A poeta desconstrói, assim, esse símbolo imperial que não é mais, ou não terá sido nunca, sinal de grandeza. Brandão, através de um esquema em paralelismo, acaba por criar trocadilhos velados, mas, na verdade, quer denunciar que o que se colocava no mar não eram mais as barcas - supostamente comerciais, mas, na verdade, desde sempre bélicas -, mas sim as armas em que se haviam transformado aquelas ("Lisboa tem barcas novas/ (...)/ Em Lisboa sobre o mar/ armas novas são 
mandadas”). O “mar” e “as barcas” são aqui reescritos por Brandão de modo a desconstruir a sua simbologia em função de um imaginário nacional. Vistos sempre como fonte de riqueza e engrandecimento do país, passam agora a ser apresentados como modos de chegar a uma guerra não assumida - que, na verdade, não começou apenas em 1961, mas quinhentos anos antes -, como transportes de homens e armas para chegar ao império além-mar e fazer guerra contra o colonizado que pedia libertação.

Em Brandão, esses símbolos de imperialidade e de riquezas são agora apresentados como veículos de chegada a uma guerra imperial mantida em África por um império imaginado quando muitas eram as vozes que se levantavam contra esse conflito e as suas atrocidades e contra o império caduco. O poema de Brandão faz lembrar as palavras de Roberto Vecchi (2010: 33) ao relacionar os conceitos de melancolia e de identidade no caso da poesia da guerra colonial portuguesa: “A escrita da Guerra Colonial é uma escrita melancólica”, já que a autora lhe imprime um tom dolente e saudoso, remetendo para os sentimentos quer de quem fica, quer de quem parte.

José Niza também cumpriu comissão militar em Angola entre 1969 e 1971, durante a qual foi escrevendo alguns poemas que publicou só em 2008 em Poemas de Guerra. O poema "Caro Luiz Vaz" (1970) (AMPGC, 2011: 359) é um misto de piada de caserna, ao gosto sexista e militar, e de denúncia de uma guerra infame. O poema é, como indica o título, uma reescrita de Camões, mais concretamente de alguns versos da Preposição de Os Lusíadas, um texto praticamente indestrutível da memória em função. Mas trata-se de uma apropriação paródica desse texto em que o poeta começa por referir que "canta um ilustre peito lusitano" e rapidamente fica claro que tipo de peito é pela comparação ao da "Mangano", ou seja, ao peito de Silvana Mangano, atriz e modelo italiana com grande projeção na época. Não se trata, portanto, de cantar os ilustres heróis lusitanos, mas a mulher amada que ficou em Portugal. Segue-se um pedido de "engenho e arte" não para louvar as glórias dos portugueses, mas para mandar "esta vil guerra àquela parte". O poeta conclui, sempre fazendo um bem combinado uso do burlesco, dizendo que não tem vocação para "esta guerra injusta/ e sem respeito".

Ora, o que José Niza aqui faz é o enviesamento total do texto de Camões, parodiando a epopeia gloriosa dos portugueses na medida em que desconstrói não só a mensagem de grandiosidade veiculada pela obra, como a própria figura do autor. Com este poema, a grandiloquência de Os Lusíadas é rebaixada ao nível de piada da caserna, retirando ao texto cânone por excelência da literatura portuguesa o seu valor de instrumento de imperialização do espaço português. Mas é também desconstruída a imagem de homem de letras e de armas sempre associada a Camões, pois, neste caso, o sujeito poético não defende esse ideal guerreiro, antes o desconstrói totalmente ao recusar-se veementemente a fazer parte daquela guerra que considera "vil, "injusta" e "sem respeito". Pode 
aqui ler-se, até, que esse desrespeito é tanto para com os portugueses que lutam e morrem numa guerra insana, como para com os colonizados que desde 1961 se batem pela sua libertação (de notar que, quando Niza inicia a sua comissão em Angola, a Guerra já começara há oito anos).

José Niza, ao apoderar-se do cânone português retalhando-lhe o sentido através da paródia, pretende denunciar que "Camões nos tinha cantado como cabeça (da Europa)”, mas há muito que não éramos mais do que "o finisterra”. Por isso mesmo, a guerra inútil denunciada no poema era uma tentativa vã de manter uma "realidade de nebulosas heranças imperiais e, ao mesmo tempo, uma abstração que toda a realidade quotidiana negava” (Ribeiro, 2004: 169), principalmente quando se passava dois anos de comissão obrigatória numa guerra movida por ideais em que não se acreditava.

Observamos, nos três poetas, uma forte inclinação para pôr em causa elementos emblemáticos da memória em função, destruindo-os ou exigindo a sua desmitificação. Ao mesmo tempo, eles recordam-nos o não-dito (a memória em depósito), o esquecimento das múltiplas derrotas ao longo da história e o seu significado.

\section{Pós-memória dos filhos da geração da Guerra Colonial}

Para compreender melhor o funcionamento da memória comunicativa de que fala Jan Assmann, é preciso subdividi-la. As três ou quatro gerações vivas não partilham lembranças de uma forma homogênea, havendo uns experienciado na própria pele os acontecimentos traumáticos (primeira geração), outros tendo sido suas testemunhas durante a infância (geração uma e meia) e outros, ainda, tendo nascido após o conflito bélico, sendo herdeiros indiretos das histórias contadas pelos mais velhos (segunda geração e seguintes).

Tendo analisado, no capítulo anterior, poemas da primeira geração, debruçar-nos-emos agora sobre obras artísticas da geração uma e meia (Ana Vidigal) e segunda (António Ferreira). Suleiman (2002) propõe o termo 1.5 generation para falar especificamente de crianças judias sobreviventes do holocausto que sofreram um trauma antes da formação de uma identidade estável associada à idade adulta. O termo é útil para falar também de crianças sobreviventes de outros conflitos bélicos, tendo, contudo, em conta que o impacto psicológico depende muito do local em que se vive. A diferença entre as crianças judias e as crianças portuguesas é que aquelas foram testemunhas diretas de violências múltiplas e estas viveram a Guerra Colonial apenas de forma indireta, visto que acontecia noutro continente e se fazia notar apenas por ausências. Suleiman sublinha que é necessário descrever cada caso na sua particularidade. Isto também inclui uma distinção de três faixas etárias diferentes: (1) crianças de mais ou menos 0-3 anos, demasiado jovens para lembrar; (2) crianças de aproximadamente 4-10 anos, capazes de lembrar, mas demasiado jovens para 
compreender; e (3) crianças de 11-14 anos, capazes já de compreender, mas ainda demasiado jovens para tomar decisões ou serem responsabilizadas pelas decisões que se viram obrigadas a tomar durante o conflito (Suleiman, 2002: 283).

Para Marianne Hirsch (2008) o termo “pós-memória” visa especificamente a relação que a segunda geração estabelece com as experiências traumáticas da primeira, mas acreditamos que também se aplica à primeira faixa etária da geração 1.5 que não tem lembranças próprias da guerra e que, além disso, não partilhou o palco traumático. Estas crianças crescem rodeadas de estórias, imagens e certos comportamentos difíceis de compreender visto que o trauma inscrito no corpo dos pais faz-se notar neles também de maneira não-verbal através de pesadelos, sinais de doença, dores físicas, depressões ou outros transtornos psicológicos. Por essa razão, as obras artísticas desta geração, muitas vezes, procuram representar o efeito de longa duração produzido pela convivência íntima com pessoas traumatizadas, ao mesmo tempo que evidenciam que a memória transmitida no seio da família é sempre mediada por imagens e narrativas que circulam no ambiente público (Hirsch, 2008: 112). Portanto, a pós-memória partilha com a memória direta das testemunhas não só a capacidade de questionar a guerra, mas também de subverter elementos mais antigos da memória cultural. Contudo, expressões de pós-memória acrescentam, muitas vezes, uma componente afetiva diferente: a da difícil convivência com os veteranos da guerra no seio da família, que é também uma preocupação central em Ana Vidigal.

Nascida em 1960, no Porto, Ana Vidigal pertence à segunda faixa etária da geração 1.5. O pai, arquiteto de profissão, foi combatente na Guerra Colonial durante dois anos e meio, de 1967 a 1969, na Guiné. Quando embarcou, Ana ainda não tinha feito sete anos, mas retém memória própria desta época. Para ela, a ausência dos homens nas famílias é uma memória partilhada por praticamente toda a sua geração, como afirma numa entrevista (Ribeiro, 2010). A sua instalação "Penélope" (2000), elaborada para a exposição Um Oceano Inteiro para Nadar, consiste numa cama cujo cobertor é um patchwork dos aerogramas e cartas que os seus pais trocaram entre si durante o serviço militar do pai. Todas as cartas estão dentro dos envelopes envoltos em sacos plásticos e agrafados uns aos outros (Rosengarten e Soares, 2003). Desta maneira, os nomes e endereços dos pais da artista são visíveis, no entanto, o conteúdo das cartas é invisível e fica relegado à intimidade do casal, também representada pela cama, lugar simbólico do amor e do sexo. No entanto, a intimidade encontra-se agora invadida violentamente pela política que defende uma guerra em terras longínquas que continua reclamando para si. A instalação coloca o/a espectador/a na perspetiva da criança que vê a mãe sempre sozinha e angustiada, sentada ou deitada na cama, lendo e relendo as cartas do marido ausente, tal como 
Penélope esperava Ulisses, denunciando, assim, a brutalidade do Estado que separa as famílias e as expõe ao medo da iminência da perda.

Já a instalação "Void" (2007), elaborada para o Project Room da ArteLisboa, desloca o olhar do espectador para o quarto da filha desse homem mobilizado na Guiné (Brito e Dinis, 2009). Encontram-se no quarto uma cama com uma colcha semelhante à de "Penélope", com fotografias agrafadas em patchwork, e uma almofada com uma imagem da artista com uma boina militar, várias fotografias ${ }^{3}$ do pai emolduradas e penduradas na parede, um televisor que mostra um vídeo que o pai da artista filmou na Guiné e uma janela que dá para a imagem do quarto do pai em Nova Lamego. Numa outra parede, ainda há uma série de babetes do irmão mais novo da artista, decoradas com cartas do pai que a mãe lia para os filhos enquanto jantavam (Ribeiro, 2011).

O espaço íntimo da criança está, assim, totalmente invadido por imagens e histórias do pai ausente e da guerra que o tinha levado, não deixando quase lugar para outras histórias próprias e brinquedos adequados à sua idade, salvo poucos livros infantis numa estante. O medo da morte do pai acompanha todos os elementos íntimos da vida familiar, como o jantar e os sonhos noturnos. A artista, ao tornar públicas estas memórias, os aerogramas, as cartas, as fotografias, rompe com a ideia de que estes são assuntos domésticos a permanecer dentro das quatro paredes e denuncia como a guerra também foi das mulheres e das crianças que ficaram. Deste modo, Ana Vidigal desloca a sua denúncia em relação aos/às poetas da primeira geração. Se o alvo da denúncia destes era, sobretudo, a falsidade com que o Estado Novo legitimava a Guerra Colonial, apoiando-se na alegada grandeza imperial de Portugal a despeito de todas as evidências que a contrariavam, o alvo de Vidigal é o estrago emocional desta política ditatorial na vida íntima das pessoas. Neste sentido, as instalações de Vidigal apresentam caraterísticas típicas da sua geração.

Ao contrário de Vidigal, o realizador António Ferreira, nascido em Coimbra em 1970, não tinha idade suficiente durante a guerra para reter lembranças próprias ${ }^{4}$. De facto, a ideia para o seu filme de curta-metragem Deus não quis (2007) não nasceu de vivências próprias, mas da iniciativa do roteirista Miguel Triantafillo (Vieira, 2015). A curta retoma a canção popular "Laurindinha", cantada durante décadas de salazarismo, confrontando-a com imagens fílmicas contrárias.

\footnotetext{
3 Para Hirsch (2008: 107), o uso de fotografias é típico de obras de pós-memória. Não possuindo memória própria, os/as autores/as confrontam-se com a falsa promessa das fotografias de oferecer acesso aos eventos.

$4 \mathrm{O}$ realizador não parece ter feito referências a familiares diretos que tenham vivido a guerra. Invoca, antes, o conflito bélico no Iraque e o apoio de Portugal através da decisão do então primeiro-ministro Durão Barroso como o motivo direto para a criação da curta. Usou o exemplo português da Guerra Colonial para denunciar as injustiças da guerra e as decisões políticas de enviar gente para o perigo constante que é o palco de guerra (Vieira, 2015).
} 
O filme é organizado em dois eixos temporais. O primeiro, muito mais extenso, é composto por vários momentos do ano de 1970 em que um jovem rapaz é chamado à tropa e volta numa cadeira de rodas, portador de deficiência motora. O segundo, composto apenas por breves instantes, mostra o ex-militar no presente, já com cabelo grisalho, ainda sentado na sua cadeira de rodas e vendo fotografias da época (também significativas na obra de Vidigal) no ecrã do seu computador. O filme indica, desta forma, que a história que se desenrola no primeiro eixo temporal é a memória direta de quem a viveu, ao mesmo tempo que coloca os/as espectadores/as na posição de terceiros que recebem a história e as imagens por via de outra pessoa, perspetiva típica da segunda geração e da primeira faixa etária da geração 1.5 .

Uma festa de despedida de soldados, numa taberna do Coentral em 1970, é o momento de convergência de vários elementos significativos do filme. O jovem soldado dança com a sua namorada e toca-se e canta-se de modo leviano a canção popular "Laurindinha", como se de uma homenagem aos rapazes se tratasse: "Oh Laurindinha, vem à janela./ Ver o teu amor, (ai ai ai) que ele vai p'ra guerra./ Se ele vai p'ra guerra, deixá-lo ir./ Ele é rapaz novo, (ai ai ai) ele torna a vir./ Ele torna a vir, se Deus quiser./ Ainda vem a tempo, (ai ai ai) de arranjar mulher”. Na sequência, há vários elementos de grande carga semântica que retomam a letra para depois subvertê-la. A janela é um deles: os namorados tocam o vidro da janela da taberna em jeito de despedida, ele do lado de dentro, ela do lado de fora, depois da festa que anuncia já a rutura e o incontornável afastamento que os vai separar simbolizado pelo vidro. Retoma-se este elemento na despedida dos dois na janela aberta do carro que leva o jovem: a rapariga entrega-lhe uma carta de amor, outro elemento de grande carga semântica que já aparecia nas obras de Vidigal e que simboliza, ao mesmo tempo, proximidade emocional e distância física. Seguem-se cenas em que os namorados, separados geograficamente, escrevem e recebem cartas, enviam-se fotos que se intercalam no filme (originais da época e recriações em que aparece o rapaz).

O ponto de transição da história constitui o momento em que vemos o jovem soldado numa cama de hospital, ferido. Do outro lado do mar, a rapariga lê no seu quarto, sentada na cama, a carta que notifica a lesão de guerra do namorado e esconde-a, finalmente, debaixo da almofada. À semelhança das instalações de Vidigal, o quarto de dormir transforma-se no palco de dramas emocionais originados pela política do Estado Novo; a cama e a almofada tornam-se objetos chave em que se refletem as lesões emocionais. Na cena do regresso do soldado à aldeia, a rapariga corre ao lado do carro em que chega o jovem, contudo, desta vez, o jovem não a olha, nem abre a janela. A rapariga ainda tenta visitá-lo em casa, batendo várias vezes na janela da sala, mas ele recusa vê-la. A janela já não une, separa. A música continua jogando cinicamente com a deficiência motora do jovem que deus não quis que voltasse 
como partiu. Nunca se volta de uma guerra como se parte, trazem-se inscritas nos corpos mazelas emocionais e/ou físicas irreparáveis. Assim, a letra desta canção popular portuguesa, que ocupa um lugar na memória cultural do país até aos dias de hoje, é desconstruída, revelando que a promessa em que tantas Laurindinhas acreditavam ingenuamente não era, na época, mais do que um pérfido instrumento de propaganda política e, paralelamente, um símbolo da alienação social em relação à Guerra Colonial.

\section{Conclusão}

Retomando os conceitos de Jan Assmann e Aleida Assmann, podemos concluir que os poetas da primeira geração, além de condenar a violência da guerra, recorrem a uma estratégia que visa desconstruir os mitos nacionais com que o Estado Novo continuava a justificar a sua presença em África e a Guerra Colonial e que não passavam, afinal, de uma ficção da propaganda nacional. Desta maneira, propõem uma reescrita da memória cultural do país. A sua estratégia visa, em primeiro lugar, a sepultação de alguns significados atribuídos a elementos contidos na memória em função. No entanto, em segundo lugar, também visa, implicitamente, a exumação de elementos silenciados, relegados à memória em depósito, particularmente a memória das derrotas. Esta ação de limpeza da memória cultural proposta pelos poetas, se repetida muitas vezes por muitas vozes, pode acabar por transformar a autoimagem da Nação, sobretudo se for retomada e aceite pela classe política e pelos meios de comunicação social. Se isto já aconteceu ou não, é difícil determinar. Diríamos que é um processo iniciado a ser continuado pelas gerações seguintes.

A geração 1.5 e a segunda geração, pelo menos nos exemplos que escolhemos, parecem ter-se desprendido da mitologia nacional portuguesa. Pelo menos a falsidade da grandiloquência deixa de ser tema das suas obras, optando por subverter outros aspetos que acabaram também por fazer parte de um imaginário coletivo, como a canção popular ou o espaço doméstico como espaço privado e da mulher, por excelência. Assim, a preocupação, agora, são os elementos contidos na memória comunicativa: os estragos emocionais das várias gerações vivas e os traumas com que vivem e que não são reconhecidos pelas novas elites políticas pós 25 de abril que optaram por silenciar o final inglório do imperialismo português. Segundo Eduardo Lourenço (2014: 67), o novo governo expurgou-se da culpa histórica, visto que "[f]oi tudo posto na conta de Salazar. E Salazar na conta de ninguém”. Para o pensador, o desastre da Guerra Colonial "lido às avessas, se converteu no ato fundador da nova democracia portuguesa” (Lourenço, 2014: 68). Portanto, atualmente, a identidade política portuguesa - entendemos "identidade política" como um conceito mais estreito que "identidade nacional" - é fundada sob o silenciamento de um "desastre" 
cujo reconhecimento oficial só aos poucos é reivindicado. Neste sentido, tanto a literatura, como outras artes têm feito um extraordinário trabalho de reescrita da história portuguesa, contribuindo para uma memória cultural mais ampla, como aqui ficou demostrado.

\section{Referências bibliográficas}

ASSMANN, Aleida (2006), Der lange Schatten der Vergangenheit. Erinnerungskultur und Geschichtspolitik, München, C. H. Beck.

ASSMANN, Jan (2007 [1997]), Das kulturelle Gedächtnis. Schrift, Erinnerung und politische Identität in frühen Hochkulturen, München, C. H. Beck.

BRITO, Rui, DINIS, Hugo (coords.) (2009), Ana Vidigal, Lisboa, Galeria 111.

CAETANO, Marcello José das Neves Alves (1973), Razões da presença de Portugal no Ultramar, Lisboa, Oficinas Gráficas da S.E.I.T..

FERREIRA, António (2007), Deus não quis, Argumento de Miguel Triantafillo, Persona Non Grata Pictures, Portugal, 15 minutos

HIRSCH, Marianne (2008), “The Generation of Postmemory”, Poetics Today, 29 (1), pp. 103-128.

LOURENÇO, Eduardo (2009 [1978]), O Labirinto da Saudade, Lisboa, Gradiva.

LOURENÇO, Eduardo (2014), Do Colonialismo como Nosso Impensado, Lisboa, Gradiva.

MATTOSO, José (1998), A Identidade Nacional, Lisboa, Gradiva.

RIBEIRO, Anabela Mota (2010), “Ana Vidigal é pintora e nunca lhe passou pela cabeça ter filhos”, Público (12/07/2010), disponível em: https://www.publico.pt/culturaipsilon/noticia/ ana-vidigal-e-pintora-e-nunca-lhe-passou-pela-cabeca-ter-filhos-1446411 [consultado em: 22/02/2016].

RIBEIRO, Margarida Calafate (1998), "Percursos Africanos: A Guerra Colonial na Literatura Pós-25 de Abril”, Portuguese Literary \& Cultural Studies, 1, pp. 125-152.

RIBEIRO, Margarida Calafate (2004), Uma História de Regressos: Império, Guerra Colonial e Pós-Colonialismo, Porto, Afrontamento.

RIBEIRO, Margarida Calafate, VECCHI, Roberto (org.) (2011), Antologia da Memória Poética da Guerra Colonial, Porto, Afrontamento.

SANTOS, Boaventura de Sousa (1999), Pela Mão de Alice: O social e o político na pós-modernidade, Porto, Afrontamento.

SANTOS, Boaventura de Sousa (2006), "Entre Próspero e Caliban: colonialismo, pós-colonialismo e inter-identidade", in Boaventura de Sousa Santos (org.), A Gramática do Tempo: Para uma nova cultura política, Porto, Afrontamento, pp. 211-255.

SULEIMAN, Susan Rubin (2002), "The 1.5 Generation: Thinking About Child Survivors and the Holocaust", American Imago, 59 (3), pp. 277-295.

VECCHI, Roberto (2010), Excepção Atlântica: Pensar a literatura da Guerra Colonial, Porto, Afrontamento.

ROSENGARTEN, Ruth, OLIVEIRA, Luísa Soares (2003), Ana Vidigal, Lisboa, Assírio \& Alvim.

VIEIRA, João (2015), “Como António Ferreira Aprendeu A 'Respirar (Debaixo D'água)"”, Shifter (29/09/2015), disponível em: http://shifter.pt/2015/09/como-antonio-ferreira-aprendeu-a-respirar-debaixo-dagua/ [consultado em: 22/02/2016]. 